\title{
Independent prognostic value of HIF-1 $\alpha$ expression in radiofrequency ablation of lung cancer
}

\author{
JUN WAN, XIEAN LING, ZHANPENG RAO, BIN PENG and GUANGGUI DING \\ Department of Thoracic Surgery, The Shenzhen People's Hospital, \\ The Second Clinical Medicine College of Jinan University, Shenzhen, Guangdong 518020, P.R. China
}

Received February 1, 2019; Accepted September 20, 2019

DOI: $10.3892 / \mathrm{ol} .2019 .11130$

\begin{abstract}
Radiofrequency ablation (RFA) is widely used in the treatment of lung cancer. Hypoxia-inducible factor- $1 \alpha(\mathrm{HIF}-1 \alpha)$ is a crucial transcription factor regulating oxygen homeostasis that is involved in tumor cell metastasis. The present study investigated the impact of HIF-1 $\alpha$ expression and other factors, such as postoperative blood $\mathrm{CD}^{+} / \mathrm{CD}^{+}$ ratio, on the prognosis of patients with lung cancer who had received RFA treatment. A total of 80 patients with lung cancer were recruited between January 2011 and October 2016 at The Shenzhen People's Hospital. Lung cancer was confirmed following pathological or histological examination. All patients underwent RFA treatment. Patients were followed up for 6-66 months. HIF-1 $\alpha$ expression in lung cancer tissues was assessed by immunohistochemistry. Multivariate survival analysis was performed using Cox proportional hazards model. The results demonstrated that HIF-1 $\alpha$ level was low in 36 patients and overexpressed in 44 patients with lung cancer. Kaplan-Meier (KM) curve analysis demonstrated that the overall survival time of patients with high HIF-1 $\alpha$ expression was significantly shorter compared with patients with low HIF-1 $\alpha$ expression $(\mathrm{P}<0.05)$. Furthermore, the results from the KM model and log-rank test revealed that age, Union for International Cancer Control stage, primary or metastatic cancer, chemotherapy, postoperative blood $\mathrm{CD} 4^{+} / \mathrm{CD}^{+}$ratio, Eastern Cooperative Oncology Group performance status and HIF-1 $\alpha$ expression had significant effects on overall survival of patients with lung cancer. The results from Cox analysis demonstrated that high HIF- $1 \alpha$ expression, advanced age, clinical staging and chemotherapy were independent risk factors for the prognosis of lung cancer following RFA treatment, and that high HIF-1 $\alpha$ expression was associated
\end{abstract}

Correspondence to: Dr Guanggui Ding, Department of Thoracic Surgery, The Shenzhen People's Hospital, The Second Clinical Medicine College of Jinan University, 1017 DongMen North Road, Luohu, Shenzhen, Guangdong 518020, P.R. China

E-mail: wjqe003322@163.com

Key words: radiofrequency ablation, lung cancer, prognosis, hypoxia-inducible factor- $1 \alpha$ with the increased risk (5.91-fold) of mortality. In conclusion, the present study demonstrated that HIF-1 $\alpha$ expression was increased in lung cancer tissues and was associated with the prognosis of patients with lung cancer who were treated with RFA. These findings suggest that HIF-1 $\alpha$ expression may be considered as a marker for evaluating the prognosis of these patients.

\section{Introduction}

Lung cancer is a common malignancy with high morbidity and mortality rates. According to a survey by Chen et al (1), the incidence of lung cancer in China ranks now first among all types of cancer. Lung cancer also presents a high rate of metastases $(2,3)$. Metastasis is a complex multi-step process that comprises numerous genes and several factors, including angiogenesis factors, extracellular metal matrix proteases and adhesion molecules $(4,5)$. The development of lung cancer involves many tumor suppressor genes that are downregulated, such as p53 (6), $\mathrm{Rb}(7)$ and Fhit (8), as well as the abnormal overexpression of oncogenes, such as CDCA7 (9), KIF20A (10) and CCNB2 (11). Non-small cell lung carcinoma (NSCLC), which is a type of lung cancer, is divided into four histological subtypes, including adenocarcinoma, squamous cell carcinoma, large cell carcinoma, and NSCLC not otherwise specified (12). Adenocarcinoma and squamous cell carcinoma represent $\sim 80 \%$ of all NSCLC cases (13). The various types of lung cancer possess distinct histological features and display different biological behavior (14), which influence the choice of treatment and the prognosis of patients with lung cancer (15). Determining the molecular profiles of all types of lung cancer in order to develop novel therapies is therefore essential (16). The present study aimed to investigate the effect of hypoxia on all histological types of lung cancer. It has been demonstrated that a hypoxic microenvironment can inhibit tumor apoptosis and promote DNA repair, increasing therefore cancer invasion and metastasis and promoting radiochemotherapy resistance $(17,18)$.

HIF- $1 \alpha$ is a crucial transcription factor that regulates oxygen homeostasis, serving therefore a pivotal role in tumor hypoxia (19). An increased expression of HIF-1 $\alpha$ has been observed in various types of human cancer, including NSCLC, and can be associated with poor prognosis in some cases $(20,21)$. HIF-1 $\alpha$ level is regulated by hypoxic factors, 
such as limited oxygen concentration, and is associated with tumor differentiation and invasion $(22,23)$. Radiofrequency ablation (RFA) is a minimally-invasive interventional treatment for local tumors that promotes tumor cell apoptosis and necrosis through high temperatures (24). RFA also stops blood supply to the peripheral blood vessels of the tumor in order to reduce metastasis (25). In addition, RFA has demonstrated satisfactory clinical effects in the treatment of patients with primary lung cancer and lung metastases (26). Subsequently, the 5-year survival rate of patients with lung cancer is $25-61 \%$ (27). The 3-year survival rate of patients with lung cancer reaches $57 \%$ when radiotherapy and chemotherapy are combined (28). Although RFA is effective for the treatment of lung cancer, it also induces several complications that can severely affect the prognosis of patients (29-32). The results from our previous study demonstrated that local recurrences of lung cancer caused by the overgrowth of residual tumor following RFA treatment are driven by HIF-1 $\alpha$ (33). However, whether HIF-1 $\alpha$ could be considered a prognostic factor for patients with lung cancer following RFA treatment remains unknown. The present study analyzed the clinical data and survival time of 80 patients with lung cancer who underwent RFA in order to investigate the effect of HIF- $1 \alpha$ expression on the prognosis of these patients.

\section{Materials and methods}

Clinical data collection. A total of 80 patients diagnosed with lung cancer by histopathological analysis and who had received RFA treatment between January 2011 and October 2016 at the Department of Thoracic Surgery of The Shenzhen People's Hospital were included in the present study. The cohort consisted of 66 men and 14 women with an average age of $62.14 \pm 9.41$ years (age range, $41-80$ years). Of the 80 patients, 61 patients were smokers or ever smokers (76.32\%). The inclusion criteria were as follows: i) Patients unable to undergo or unsuitable for surgical treatment due to multiple tumors, recurrences and severe cardiovascular disease as confirmed by pathological or cytological examination (including percutaneous biopsy, lymph node biopsy, fiberoptic bronchoscopy brushing and biopsy, pleural effusion cytology and sputum cytology); ii) patients with complete clinical data; and iii) patients with definite staging. Patients with second primary malignancy and who were lost during follow-up were excluded. During the surgery, tumor tissues and tumor adjacent tissues (located $2 \mathrm{~cm}$ way from tumors) were collected. The baseline characteristics of all patients are summarized in Table I. Following RFA treatment tissue samples were stained with hematoxylin and eosin (H\&E) and examined for pathological changes by light microscopy. The ablation zone was treated by needle biopsy to evaluate the expression of HIF-1 $\alpha$ by immunohistochemistry (IHC). Peripheral blood $(10 \mathrm{ml})$ was collected at 1 week following RFA and directly sent to the laboratory for the analysis of $\mathrm{T}$ lymphocyte subsets $\left(\mathrm{CD} 4^{+} / \mathrm{CD}^{+}\right)$. Their association with the prognosis of patients with lung cancer was also analyzed.

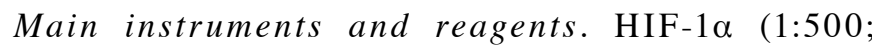
cat. no. RM242) rabbit anti-human monoclonal antibody and
SP immunoassay kit were purchased from Boster Biological Technology. The goat anti-rabbit secondary antibody (1:1,000; cat. no. BA1056) was provided by Wuhan Boster Biological Engineering Technology Co., Ltd. Fluorescein isothiocyanate- and antigen-presenting cells-CD4 and CD8 were purchased from BD Biosciences. Inverted Microscope (Olympus Corporation). The tissue embedder (Sakura), slicer (Leica Microsystems GmbH), oscillator (Shanghai Jinghong Experimental Equipment Co., Ltd.), plastic staining frame (Fuzhou Maixin Biotech Co., Ltd.), computer image analysis system (HP), expandable anchor RF electrode needle (Beijing Blade Photoelectric Technology Development Co., Ltd.). A total of 12 microelectrode needles can be released radially with a diameter of $4.0 \mathrm{~cm}$, when fully opened to cover the ablation area as much as possible, the local temperature can reach $90-100^{\circ} \mathrm{C}$ during treatment and the thermal coagulation necrosis diameter was 5-6 cm), RF-2000 radiofrequency treatment instrument (Beijing Blade Photoelectric Technology Development Co., Ltd.; radiofrequency, $500 \mathrm{kHz}$; maximum output power, $200 \mathrm{~W}$ ) and Siemens 64 row SOMATOM Perspective dual source spiral CT (Siemens, AG were used in experiments.

RFA treatment. All the patients undergoing lung RFA were admitted as inpatients at the Department of Thoracic Surgery of The Shenzhen People's Hospital and placed in observation for a minimum of one night. All patients completed at least one post-procedure chest radiograph. A total of 57 patients received lung RFA under general anesthesia, whereas 23 patients were treated under local anesthesia. Briefly, CT-guided radiofrequency needle was inserted into the lung cancer tissue and the microelectrode was opened to connect the radiofrequency current. The average duration of the RFA treatment was 50 min with a mean and median impedance of 439 and 446 units, respectively. Technical success was defined as complete ablation of all target lesions. When the RFA operation was completed, a needle biopsy was performed immediately for the detection of HIF-1 $\alpha$ expression.

Patients' follow-up. The follow-up (6-66 months) was performed by electronic medical record inquiry and telephone calls. Overall survival was calculated from the first treatment with RFA (not from the diagnosis of lung cancer). The association between HIF- $1 \alpha$ expression and patient prognosis was analyzed by unpaired two-tailed Student's t-test. Kaplan-Meier (KM) analysis was used to construct the survival curve. Cox proportional hazards model was applied for multifactor survival analysis.

$I H C$. The dissected tissue was fixed in $4 \%$ polyoxymethylene for two days, decalcified in $10 \%$ EDTA at $48^{\circ} \mathrm{C}$ for 2 weeks and sliced into $5-\mu \mathrm{m}$ sections. Sections were subjected to antigen retrieval in sodium citrate buffer $(1 \mathrm{M}, \mathrm{pH} 6.0)$ at $99^{\circ} \mathrm{C}$ for $20 \mathrm{~min}$ and incubated with primary antibody against HIF-1 $\alpha(1: 1,000$; cat. no. RM242; Boster Biological Technology) overnight at $4^{\circ} \mathrm{C}$. The slides were then incubated with a biotin-conjugated goat anti-rabbit secondary antibody (1:1,000; cat. no. BA1003; Wuhan Boster Biological Engineering Technology Co., Ltd.) at room temperature for $45 \mathrm{~min}$. The slides were examined with a Nikon Eclipse Ti light microscope under a $x 40$ objective 
Table I. Univariate analysis of the clinical characteristics of patients with lung cancer.

\begin{tabular}{|c|c|c|c|c|}
\hline Characteristics & Number & Median survival time (days) & $\chi^{2}$ value & P-value \\
\hline Sex & & & 1.035 & 0.596 \\
\hline Male & 66 & 578 & & \\
\hline Female & 14 & 432 & & \\
\hline Age (years) & & & 11.769 & 0.001 \\
\hline$<60$ & 30 & 983 & & \\
\hline$\geq 60$ & 50 & 480 & & \\
\hline Primary or metastasis & & & 32.387 & $<0.001$ \\
\hline Primary cancer & 67 & 836 & & \\
\hline Metastatic cancer & 13 & 356 & & \\
\hline UICC stage (67 cases) & & & 58.084 & $<0.001$ \\
\hline $\mathrm{I} / \mathrm{II}$ & 34 & 1,124 & & \\
\hline III/IV & 33 & 467 & & \\
\hline Postoperative blood $\mathrm{CD}^{+} / \mathrm{CD}^{+}$ & & & 83.053 & $<0.001$ \\
\hline$\leq 1.65$ & 47 & 457 & & \\
\hline$>1.65$ & 33 & 1,145 & & \\
\hline Chemotherapy & & & 3.967 & 0.042 \\
\hline$<3$ cycles & 16 & 516 & & \\
\hline$\geq 3$ cycles & 23 & 813 & & \\
\hline ECOG rating & & & 51.674 & $<0.001$ \\
\hline 0 & 13 & 1,145 & & \\
\hline 1 & 24 & 983 & & \\
\hline 2 & 31 & 480 & & \\
\hline 3 & 12 & 301 & & \\
\hline Smoking & & & 0.326 & 0.568 \\
\hline Yes & 61 & 568 & & \\
\hline No & 19 & 578 & & \\
\hline HIF- $1 \alpha$ expression & & & 79.266 & $<0.001$ \\
\hline Low expression & 36 & 1,124 & & \\
\hline High expression & 44 & 438 & & \\
\hline
\end{tabular}

ECOG, Eastern Cooperative Oncology Group; HIF-1 $\alpha$, hypoxia-inducible factor-1 $\alpha$; UICC, Union for International Cancer Control.

(Nikon Instruments). A positive expression for HIF-1 $\alpha$ was detected when brownish-yellow particles appeared in the nucleus, membrane or cytoplasm. Results of the IHC were analyzed using semi-quantitative scoring method as described by Lin et al (34). Briefly, staining was scored as negative (-), mild $(+)$, moderate $(++)$ or strong $(+++)$ for $<1,1-10,10-50$ or $>50 \%$ of cell nuclear stain, respectively. In the present study, moderate $(++)$ and strong (+++) scores defined high HIF-1 $\alpha$ expression, whereas negative (-) and mild (+) scores defined low HIF-1 $\alpha$ expression.

$C D 4^{+} / C D 8^{+}$measurement by flow cytometry. FACS lysing solution (BD Biosciences) was used to lyse red blood cells in the peripheral blood, which was followed by two washes twice with PBS. $\mathrm{CD} 4^{+} / \mathrm{CD}^{+}$was measured using the BD Simultest $^{\mathrm{TM}}$ CD4/CD8 kit (BD Biosciences), according to manufacturer's instructions, through incubation with
FITC-labeled CD4 and PE-labeled CD8 antibody for 15-30 min at room temperature. Flow cytometry was used to analyze the residual white blood cells, and the proportions of the lymphocyte subsets were calculated using FlowJo software version 10 (FlowJo LLC).

Statistical analysis. SPSS 19.0 software (IBM Corp.) was used for data analysis. All data are expressed as the means \pm standard error of the mean. Statistical differences were analyzed by unpaired two-tailed Student's t-test for the comparison between two groups. The skewed distribution was described by median \pm interquartile range $(\mathrm{M} \pm \mathrm{Q})$. Independent samples were compared by rank sum test. All values described represent the means \pm standard deviation. KM method was used to construct the survival curve of patients with lung cancer. Significance test was based on the log-rank method. Cox ratio risk model was applied for the multivariate 
Table II. Comparison of the survival rate of patients with lung cancer after radiofrequency ablation treatment.

\begin{tabular}{lcccccc}
\hline Group & Number & 1 year $(\%)$ & 2 years $(\%)$ & 3 years $(\%)$ & 4 years $(\%)$ & 5 years $(\%)$ \\
\hline Primary cancer & 67 & & & & & \\
Stage I/II & 34 & 100.00 & 94.12 & 55.88 & 23.53 & 5.88 \\
Stage III/IV & 33 & 72.73 & 9.09 & 3.03 & 0.00 & 0.00 \\
Metastatic cancer & 13 & 46.15 & 0.00 & 0.00 & 0.00 & 0.00 \\
Total & 80 & 80.00 & 43.75 & 25.00 & 10.00 & 2.50 \\
\hline
\end{tabular}
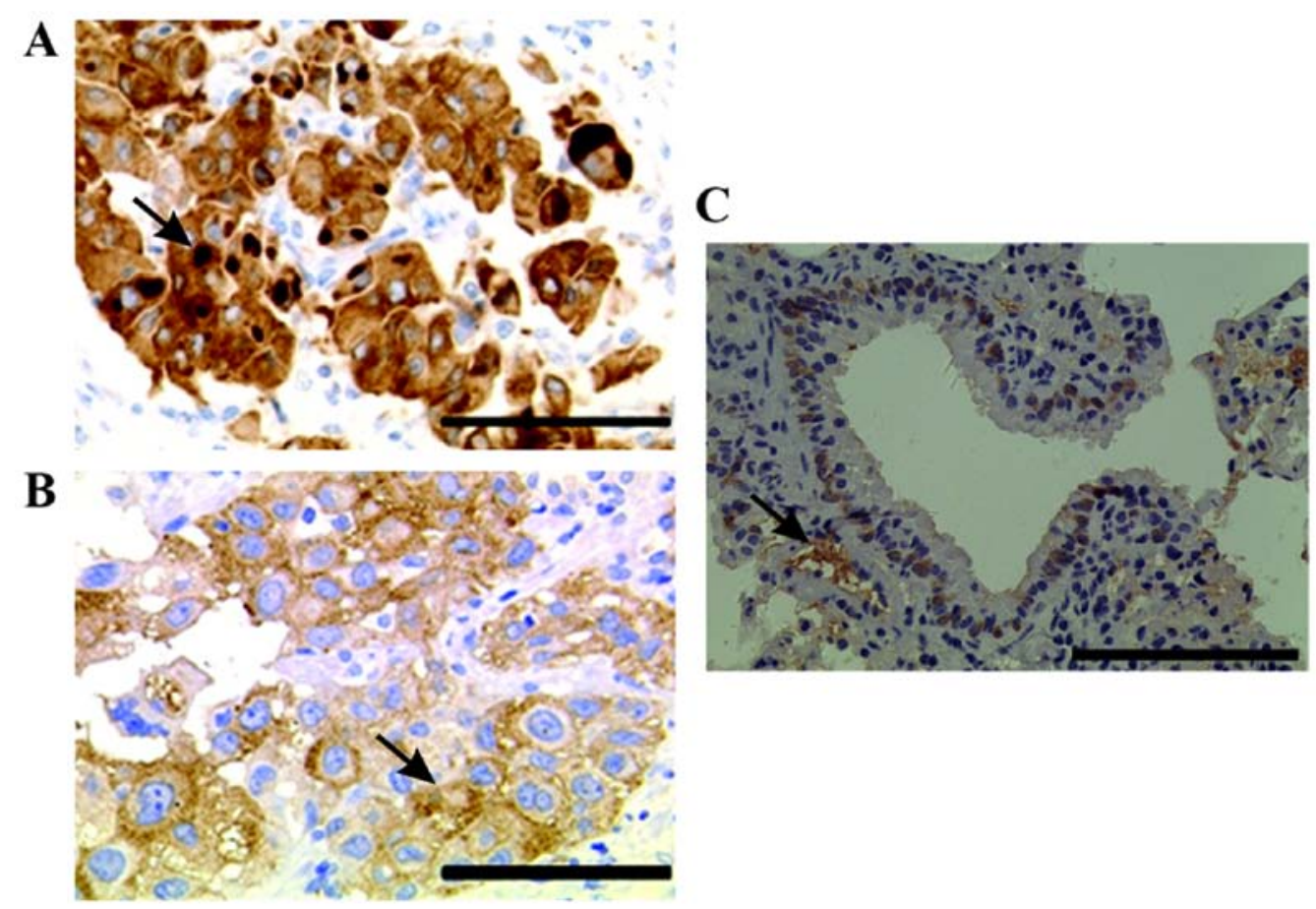

Figure 1. Immunohistochemistry of HIF-1 $\alpha$ in lung cancer and adjacent tissues. (A) Some cancer cells contained intracytoplasmic macroglobular spots strongly positive for HIF-1 $\alpha$. Magnification, x20. Scale bar, $100 \mu \mathrm{m}$. (B) Some tumor cells presented a perinuclear halo positive for HIF-1 $\alpha$. Magnification, x40. Scale bar, $50 \mu \mathrm{m}$ (C) IHC staining of tumor adjacent tissues. Magnification, x10. Scale bar, $200 \mu \mathrm{m}$ Arrows indicate the positive staining of HIF-1 $\alpha$. HIF-1 $\alpha$, hypoxia-inducible factor- $1 \alpha$.

survival analysis. $\mathrm{P}<0.05$ was considered to indicate a statistically significant difference.

\section{Results}

Patient characteristics. A total of 80 patients with lung cancer were included in the present study (Table I). The median age of the patients was $61.6 \pm 9.8$ (range, 41-80) years. The cohort consisted of 66 men $(82.5 \%)$ and 14 women $(17.5 \%)$. Furthermore, 61 patients were smokers or ever-smokers (76.3\%). The Eastern Cooperative Oncology Group (ECOG) performance status was used to assess the patient's physical condition and the score of all patients was $<3$. A total of 13 patients $(16.3 \%)$ suffered from metastatic pulmonary cancer. According to the results from the survival rate, no patients with metastatic cancer and stage III/IV primary cancer (according to The Eighth Edition of TNM Staging of Lung Cancer) survived for 5 years (35), and only two patients with stage I/II primary cancer survived for 5 years (Table II). The overall 5-year survival rate was only $2.5 \%$ (Table II).
HIF-1 $\alpha$ expression in lung cancer tissues. The results demonstrated that HIF-1 $\alpha$ was mainly localized in the nucleus and cytoplasm of lung cancer cells (Fig. 1A). Furthermore, only little HIF-1 $\alpha$ expression was detected in normal lung tissues (Fig. 1C). In addition, certain cancer cells containing intracytoplasmic macroglobular spots were strongly positive for HIF-1 $\alpha$ (Fig. 1B), and some tumor cells exhibited a positive perinuclear aureole. Representative image of HIF-1 $\alpha$ staining is presented in Fig. 1B. Among the 80 cases of lung cancer tissues analyzed, the level of HIF-1 $\alpha$ expression was as follows: 9 cases (11.3\%) had negative staining (-), 27 cases $(33.8 \%)$ had mild staining $(+) ; 13$ cases $(16.3 \%)$ had moderate staining $(++)$, and 31 cases $(38.8 \%)$ had strong staining $(+++)$. Subsequently, among all patients with lung cancer, $36(45 \%)$ displayed low HIF-1 $\alpha$ expression and 44 (55\%) presented high HIF-1 $\alpha$ expression.

Prognostic value of HIF-1 $\alpha$ expression and other factors in patients with lung cancer treated by RFA. The follow-up time of the whole group was 6-66 months. Two patients 

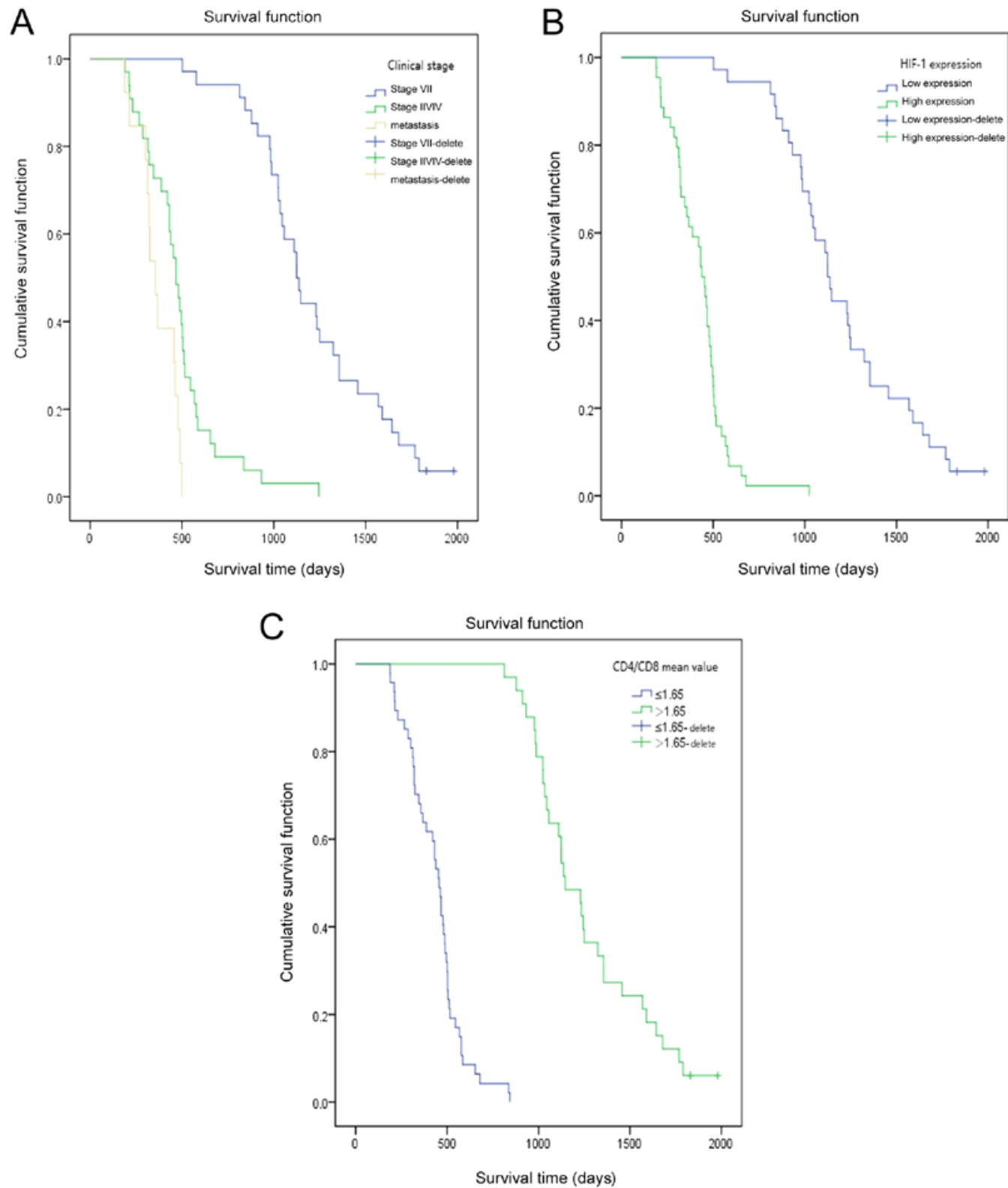

Figure 2. Overall survival of patients with lung cancer at different time points after RFA treatment. (A) Survival curve analysis of patients with lung cancer after RFA treatment according to the clinical stage. (B) Survival curve analysis of patients with lung cancer after RFA treatment according to HIF-1 $\alpha$ expression. (C) Survival curve analysis of patients with lung cancer after RFA treatment according to the postoperative level of CD4 $4^{+} / \mathrm{CD}^{+}$. HIF-1 $\alpha$, hypoxia-inducible factor-1 $\alpha$; RFA, radiofrequency ablation.

survived until the end of the follow-up. The median survival time was 573 days. The KM model and log-rank test were used to analyze the effect of clinical factors on the overall survival (OS). The results demonstrated that factors, including age, Union for International Cancer Control (UICC) stage, primary or metastatic cancer, chemotherapy, postoperative $\mathrm{CD} 4^{+} / \mathrm{CD}^{+}, \mathrm{ECOG}$ rating and HIF-1 $\alpha$ expression significantly affected the OS (Table I). The average value of $\mathrm{CD}^{+} / \mathrm{CD}^{+}$ was 1.65 (range, 0.15-4.58). Furthermore, decreased survival was observed in patients with older age, high UICC stage, lower $\mathrm{CD} 4^{+} / \mathrm{CD}^{+}$level (expression of CD 4 and $\mathrm{CD} 8$ by flow cytometry are presented in Fig. S1), high ECOG rating and high HIF-1 $\alpha$ expression (Table I). In addition, a significant difference between the OS of patients with primary cancer stage I/II and of patients with primary cancer stage III/IV was observed $\left(\chi^{2}=58.084 ; \mathrm{P}<0.001\right.$; Table II). Furthermore, a clear difference was observed in the survival rate of patients with primary and metastatic carcinoma $\left(\mathrm{P}<0.001 ; \chi^{2}=32.387\right.$; Table II). The associations between HIF- $1 \alpha$ expression, postoperative blood $\mathrm{CD}^{+} / \mathrm{CD}^{+}$or UICC staging and the OS of patients with lung cancer at different time points following RFA treatment are presented in Fig. 2. The results from KM survival curves demonstrated that patients with high HIF-1 $\alpha$ expression, high UICC stage and low $\mathrm{CD} 4^{+} / \mathrm{CD}^{+}$had a significantly shorter OS.

Associations between HIF-1 $\alpha$ expression and clinicopathological characteristics in patients with lung cancer treated by RFA. The association between HIF-1 $\alpha$ expression and the clinical characteristics of patients, including sex, age, tumor metastasis, UICC stage, ECOG rating and smoking status was evaluated. As presented in Table III, HIF-1 $\alpha$ expression 
Table III. Association between HIF-1 $\alpha$ expression and patients' clinical characteristics.

\begin{tabular}{|c|c|c|c|c|c|}
\hline Characteristics & Number & $\begin{array}{c}\text { Low HIF-1 } \alpha \\
\text { expression }(\% ; n=36)\end{array}$ & $\begin{array}{c}\text { High HIF-1 } \alpha \\
\text { expression }(\% ; n=44)\end{array}$ & $\chi^{2}$ value & P-value \\
\hline Sex & & & & 1.011 & 0.315 \\
\hline Male & 66 & $28(42)$ & $38(58)$ & & \\
\hline Female & 14 & $8(57)$ & $6(43)$ & & \\
\hline Age (years) & & & & 0.485 & 0.486 \\
\hline$<60$ & 30 & $15(50)$ & $15(50)$ & & \\
\hline$\geq 60$ & 50 & $21(42)$ & $29(58)$ & & \\
\hline Primary or metastasis & & & & 8.729 & 0.003 \\
\hline Primary cancer & 67 & $35(52)$ & $32(48)$ & & \\
\hline Metastatic cancer & 13 & $1(8)$ & $12(92)$ & & \\
\hline UICC stage (67 cases) & & & & 18.6 & $<0.001$ \\
\hline $\mathrm{I} / \mathrm{II}$ & 34 & $24(71)$ & $10(29)$ & & \\
\hline III/IV & 33 & $6(18)$ & $27(82)$ & & \\
\hline ECOG rating & & & & 45.801 & $<0.001$ \\
\hline 0 & 13 & $12(92)$ & $1(8)$ & & \\
\hline 1 & 24 & $20(83)$ & $4(17)$ & & \\
\hline 2 & 31 & $6(19)$ & $25(81)$ & & \\
\hline 3 & 12 & $2(17)$ & $10(83)$ & & \\
\hline Smoking & & & & 0.67 & 0.413 \\
\hline Yes & 61 & 29 & 32 & & \\
\hline No & 19 & 7 & 12 & & \\
\hline
\end{tabular}

ECOG, Eastern Cooperative Oncology Group; HIF-1 $\alpha$, hypoxia-inducible factor-1 $\alpha$; UICC, Union for International Cancer Control.

Table IV. Cox regression analysis of independent factors in the prognosis of patients with lung cancer.

\begin{tabular}{|c|c|c|c|c|c|c|c|}
\hline Variables & $\beta$ & SE & Wald $\chi^{2}$ & P-value & OR value & \multicolumn{2}{|c|}{$95 \% \mathrm{CI}$} \\
\hline HIF-1 $\alpha$ expression & 1.777 & 0.720 & 6.090 & 0.014 & 5.910 & 1.441 & 24.230 \\
\hline Advanced age & 0.836 & 0.277 & 9.086 & 0.003 & 2.307 & 1.340 & 3.397 \\
\hline Clinical stage & -3.548 & 1.111 & 10.202 & 0.001 & 0.029 & 0.003 & 0.254 \\
\hline Chemotherapy or not & -1.488 & 0.366 & 16.523 & $<0.001$ & 0.226 & 0.110 & 0.463 \\
\hline
\end{tabular}

CI, confidence interval; HIF-1 $\alpha$, hypoxia-inducible factor- $1 \alpha ; \beta$, estimated regression coefficient; SE, standard error; Wald, Wald statistic.

was not associated with sex, age or smoking status $(\mathrm{P}>0.05)$. However, HIF-1 $\alpha$ expression was significantly associated with tumor metastasis, UICC stage or ECOG rating $(\mathrm{P}<0.05)$ in patients with lung cancer treated with RFA.

Determination of independent factor of prognosis in patients with lung cancer by Cox regression analysis. The results from Cox regression analysis demonstrated that the high expression of HIF-1 $\alpha$, advanced age, clinical stage and chemotherapy could be considered as independent risk factors for the prognosis of patients with lung cancer following RFA treatment (Table IV). Among all cases, the OR (odds ratio) value of high HIF-1 $\alpha$ expression, advanced age, clinical staging and chemotherapy was 5.910-, 2.307-, 0.029- and 0.026-fold, respectively $(\mathrm{P}=0.014$ and $95 \%$ confidence interval $(\mathrm{CI})$,
1.441-24.230 for high expression of HIF-1 $\alpha ; \mathrm{P}=0.003$ and 95\% CI, 1.340-3.397 for advanced age; $\mathrm{P}=0.001$ and $95 \% \mathrm{CI}$, 0.003-0.254 for clinical staging; and $\mathrm{P}<0.001$ and $95 \% \mathrm{CI}$, $0.110-0.463$ for chemotherapy). Furthermore, the OR value of high HIF-1 $\alpha$ expression was higher than that of advanced age, clinical staging and chemotherapy. HIF-1 $\alpha$ expression may therefore represent a more effective independent prognostic factor in patients with lung cancer treated by RFA compared with age, clinical stage and chemotherapy.

\section{Discussion}

RFA becomes a widely accepted treatment for primary lung cancer in patients who are not candidates for subsegment resection or lobectomy (36). Compared with radiotherapy 
and chemotherapy, RFA focuses exclusively on the tumor area without causing any damage to the normal surrounding tissue (37). In addition, compared with surgical treatment, RFA is a minimally-invasive method (38). In advanced lung cancers, RFA is extremely effective for palliative care (39); however, it induces several complications, including local recurrence, which severely affects the prognosis of patients. Previous studies indicated that RFA causes deep hypoxia in the tissues that are adjacent to the resected area (40). The presence of hypoxia has been reported in several types of solid tumor and is associated with the aggressiveness, proliferation, and angiogenesis potential of the tumor (41). HIF-1 $\alpha$ is induced in hypoxia and serves a crucial role in the pathological process of inflammation, hypoxia, vascular permeability, apoptosis, pulmonary fibrosis and lung cancer $(42,43)$. In addition, HIF-1 $\alpha$ regulates the expression of $P G K-1, V E G F$ and other target genes to induce blood vessel and tissue proliferation that in turn promotes tumor growth $(44,45)$. Hypoxia inhibits HIF-1 $\alpha$ degradation and enhances HIF-1 $\alpha$ DNA binding activity, leading to high HIF-1 $\alpha$ expression. VEGF expression is therefore elevated, binds to vascular endothelial surface receptors and activates the ischemic transduction pathway $(46,47)$.

It has been reported that HIF-1 $\alpha$ expression is increased in several types of cancer, including lung, prostate, breast and colon carcinomas, which are the main causes of cancer-associated mortality (48). In the present study, 36 and 44 patients with lung cancer exhibited a low and high HIF-1 $\alpha$ expression, respectively. Furthermore, the results from KM curve demonstrated that patients with high HIF-1 $\alpha$ expression exhibited significantly shorter OS compared with patients with low HIF-1 $\alpha$ expression. The results from KM model and log-rank test demonstrated a significant effect of HIF-1 $\alpha$ expression on the OS of patients with lung cancer. The results from Cox regression analysis indicated that high HIF-1 $\alpha$ expression could be considered as an independent risk factor for patients with lung cancer following RFA treatment. Furthermore, HIF-1 $\alpha$ expression may affect tumor angiogenesis, proliferation and metabolism, which may influence tumor cell sensitivity to RFA treatment. It has been reported that HIF-1 $\alpha$ level is increased under hypoxic condition, which results in increased tumor angiogenesis via $V E G F$ and a subsequent increase in tumor size, expansion of hypoxic areas, resistance to RFA treatment and poor prognosis of patients with lung cancer (49). Consistently, the results from the present study demonstrated that patients with lower HIF-1 $\alpha$ expression presented elevated survival time compared with patients with higher HIF-1 $\alpha$ expression. In addition, HIF-1 $\alpha$ expression was significantly associated with tumor metastasis, UICC stage and ECOG rating.

Lung cancer cells secrete numerous immunosuppressive factors that can inhibit the anti-tumor immunity $(50,51)$. Furthermore, RFA treatment of lung cancer is effective and can be monitored in real time (52). A previous study demonstrated that RFA therapy for lung cancer can improve the cellular immune function, due to the direct killing effect of antigens and synergistic killing effect of cytokines released by sensitized $\mathrm{T}$ cells. This leads to the correction of immune imbalance of Th1/Th2 cells, increase $\mathrm{CD} 4^{+}$and $\mathrm{CD}^{+}$cell levels, eliminate the sources of tumor-derived inhibitors and restore the anti-tumor immunity $(53,54)$. For example, the decreased proportions of $\mathrm{CD}^{+}$cells ( $\mathrm{T}$ helper cells), CD4/CD8 ratios and $\mathrm{B}$ cells, and the increased number of $\mathrm{CD}^{+} / \mathrm{CD} 28 \mathrm{~T}$ lymphocytes and regulatory $\mathrm{T}$ (Treg) cells have been demonstrated in patients with lung cancer $(55,56)$. In the present study, the levels of $\mathrm{CD}^{+}$and $\mathrm{CD}^{+}$cells were increased following RFA treatment, which suggested that RFA treatment may restore the imbalanced immune function in patients with lung cancer. In addition, results from the KM model and log-rank test demonstrated that some factors, including age, UICC stage, primary or metastatic cancer, chemotherapy, postoperative blood levels of $\mathrm{CD}^{+} / \mathrm{CD}^{+}$, ECOG rating and HIF-1 $\alpha$ expression had a significant effect on the OS of patients with lung cancer following RFA treatment. Furthermore, Cox regression analysis revealed that high HIF-1 $\alpha$ expression, advanced age, clinical staging and chemotherapy may be considered as independent risk factors for the prognosis of patients with lung cancer after RFA treatment, which indicated that changes in T lymphocyte subsets after treatment may be associated with patient prognosis. UICC staging may also be considered as a prognostic factor for patients with lung cancer after RFA treatment. In addition, the long-term effect of treatment with RFA combined with chemotherapy for patients with advanced lung cancer was better than that of chemotherapy or RFA treatment alone. However, since the present study only included a limited number of patients, further investigation including a larger sample size is therefore required in order to confirm the prognostic value of HIF-1 $\alpha$ expression in patients with lung cancer. Although the present study determined the effect of HIF-1 $\alpha$ expression on the prognosis of patients with lung cancer after RFA treatment, the underlying mechanisms involved and the correlation between HIF-1 $\alpha$ expression and patients' immunity required further investigation.

In conclusion, the present study analyzed HIF-1 $\alpha$ expression in patients with lung cancer. The results demonstrated that patients treated with RFA and with high HIF-1 $\alpha$ expression had significantly shorter OS compared with patients with low HIF-1 $\alpha$ expression. Furthermore, high HIF-1 $\alpha$ expression was significantly associated with tumor metastasis, UICC stage and ECOG rating. HIF-1 $\alpha$ expression may therefore be considered as an effective independent prognosis factor in patients with lung cancer treated by RFA. The detection of HIF-1 $\alpha$ expression may therefore be crucial for evaluating the prognosis of patients with lung cancer who underwent RFA treatment.

\section{Acknowledgements}

Not applicable.

\section{Funding}

The present study was supported by the Natural Science Foundation of Guangdong Province (grant no. 2018A0303130247) awarded to Jun Wan.

\section{Availability of data and materials}

The datasets used and/or analyzed during the current study are available from the corresponding author on reasonable request. 


\section{Authors' contributions}

JW and GD designed the experiments. JW, XL and ZR performed the experiments. GD and BP analyzed the data. JW and XL wrote the manuscript. All authors read and approved the final version of the manuscript and agreed to be accountable for all aspects of the research to ensure that the accuracy or integrity of any part of the work are appropriately investigated and resolved.

\section{Ethics approval and consent to participate}

This study was approved by the Clinical Medical Research Ethics Committee of the First Affiliated Hospital of Anhui Medical University (approval number AF/SC-08/02.0). All patients provided informed consent prior to the study.

\section{Patient consent for publication}

Not applicable.

\section{Competing interests}

The authors declare that they have no competing interests.

\section{References}

1. Chen WQ, Zuo TT, Zheng RS, Zeng HM, Zhang SW and He J: Lung cancer incidence and mortality in China in 2013. Zhonghua Zhong Liu Za Zhi 39: 795-800, 2017 (In Chinese).

2. Wang $X$ and Adjei AA: Lung cancer and metastasis: New opportunities and challenges. Cancer Metastasis Rev 34: 169-171, 2015.

3. Riihimäki M, Hemminki A, Fallah M, Thomsen H, Sundquist K, Sundquist $\mathrm{J}$ and Hemminki K: Metastatic sites and survival in lung cancer. Lung Cancer 86: 78-84, 2014.

4. Yan X, Jiao SC, Zhang GQ, Guan Y and Wang JL: Tumor-associated immune factors are associated with recurrence and metastasis in non-small cell lung cancer. Cancer Gene Ther 24: 57-63, 2017.

5. Wan J and Wu W: Hyperthermia induced HIF-1 $\alpha$ expression of lung cancer through AKT and ERK signaling pathways. J Exp Clin Cancer Res 35: 119, 2016.

6. Zhou H, Chen A, Shen J, Zhang X, Hou M, Li J, Chen J, Zou H, Zhang Y, Deng Q, et al: Long non-coding RNA LOC285194 functions as a tumor suppressor by targeting p53 in non-small celllung cancer. Oncol Rep 41: 15-26, 2019.

7. Sasaki M, Sugio K, Kuwabara Y, Koga H, Nakagawa M, Chen T, Kaneko K, Hayashi K, Shioyama Y, Sakai S and Honda H: Alterations of tumor suppressor genes (Rb, p16, p27 and p53) and an increased FDG uptake in lung cancer. Ann Nucl Med 17: 189-196, 2003.

8. Lee TG, Jeong EH, Kim SY, Kim HR, Kim H and Kim CH: Fhit, a tumor suppressor protein, induces autophagy via 14-3-3 in non-small cell lung cancer cells. Oncotarget 8: 31923-31937, 2017.

9. Wang H, Ye L, Xing Z, Li H, Lv T, Liu H, Zhang F and Song Y: CDCA7 promotes lung adenocarcinoma proliferation via regulating the cell cycle. Pathol Res Pract 215: 152559, 2019.

10. Qian X, Song X, He Y, Yang Z, Sun T, Wang J, Zhu G, Xing W and You C: CCNB2 overexpression is a poor prognostic biomarker in Chinese NSCLC patients. Biomed Pharmacother 74: 222-227, 2015.

11. Duan J, Huang W and Shi H: Positive expression of KIF20A indicates poor prognosis of glioma patients. Onco Targets Ther 9: 6741-6749, 2016.

12. E L, Lu L, Li L, Yang H, Schwartz LH and Zhao B: Radiomics for classification of lung cancer histological subtypes based on nonenhanced computed tomography. Acad Radiol 26: 1245-1252, 2019.
13. Yeo MK, Choi SY, Seong IO, Suh KS, Kim JM and Kim KH: Association of PD-L1 expression and PD-L1 gene polymorphism with poor prognosis in lung adenocarcinoma and squamous cell carcinoma. Hum Pathol 68: 103-111, 2017.

14. Haga A, Takahashi W, Aoki S, Nawa K, Yamashita H, Abe O and Nakagawa K: Classification of early stage non-small cell lung cancers on computed tomographic images into histological types using radiomic features: Interobserver delineation variability analysis. Radiol Phys Technol 11: 27-35, 2018.

15. Lee G, Lee HY, Park H, Schiebler ML, van Beek EJR, Ohno Y, Seo JB and Leung A: Radiomics and its emerging role in lung cancer research, imaging biomarkers and clinical management: State of the art. Eur J Radiol 86: 297-307, 2017.

16. Shen R, Olshen AB and Ladanyi M: Integrative clustering of multiple genomic data types using a joint latent variable model with application to breast and lung cancer subtype analysis. Bioinformatics 25: 2906-2912, 2009.

17. Cui H, Seubert B, Stahl E, Dietz H, Reuning U, Moreno-Leon L, Ilie M, Hofman P, Nagase H, Mari B and Kruger A: Tissue inhibitor of metalloproteinases-1 induces a pro-tumourigenic increase of miR-210 in lung adenocarcinoma cells and their exosomes. Oncogene 34: 3640-3650, 2015.

18. Person RJ, Tokar EJ, Xu Y, Orihuela R, Ngalame NN and Waalkes MP: Chronic cadmium exposure in vitro induces cancer cell characteristics in human lung cells. Toxicol Appl Pharmacol 273: 281-288, 2013.

19. Goda N, Dozier SJ and Johnson RS: HIF-1 in cell cycle regulation, apoptosis, and tumor progression. Antioxid Redox Signal 5: 467-473, 2003.

20. Wan J, Chai H, Yu Z, Ge W, Kang N, Xia W and Che Y: HIF-1a effects on angiogenic potential in human small cell lung carcinoma. J Exp Clin Cancer Res 30: 77, 2011.

21. Lee CH, Lee MK, Kang CD, Kim YD, Park DY, Kim JY, Sol MY and Suh KS: Differential expression of hypoxia inducible factor-1 alpha and tumor cell proliferation between squamous cell carcinomas and adenocarcinomas among operable Non-small cell lung carcinomas. J Korean Med Sci 18: 196-203, 2003.

22. Zhang H, Zhang Z, Xu Y, Xing L, Liu J, Li J and Tan Q: The expression of hypoxia inducible factor 1-alpha in lung cancer and its correlation with P53 and VEGF. J Huazhong Univ Sci Technolog Med Sci 24: 124-127, 2004.

23. Khan MN, Haggag YA, Lane ME, McCarron PA and Tambuwala MM: Polymeric Nano-encapsulation of curcumin enhances its anti-cancer activity in breast (MDA-MB231) and lung (A549) cancer cells through reduction in expression of HIF-1 $\alpha$ and nuclear p65 (Rel A). Curr Drug Deliv 15: 286-295, 2018.

24. Jun W and Jian W: Current progression of radiofrequency ablation (RFA) in clinical application of lung cancer therapy. J Biomater Tissue Eng 9: 417-426, 2019.

25. Luo W, Zhou P and Li W: Advances in diagnosis and treatment of multiple primary lung cancer. Zhongguo Fei Ai Za Zhi 18: 640-643, 2015 (In Chinese).

26. de Baère T, Aupérin A, Deschamps F, Chevallier P, Gaubert Y, Boige V, Fonck M, Escudier B and Palussiére J: Radiofrequency ablation is a valid treatment option for lung metastases: Experience in 566 patients with 1037 metastases. Ann Oncol 26: 987-991, 2015.

27. Hiraki T, Gobara H, Iguchi T, Fujiwara H, Matsui Y and Kanazawa S: Radiofrequency ablation for early-stage nonsmall cell lung cancer. Biomed Res Int 2014: 152087, 2014.

28. Qi H and Fan W: Value of ablation therapy in the treatment of lung metastases. Thorac Cancer 9: 199-207, 2018.

29. Li G, Xue M, Chen W and Yi S: Efficacy and safety of radiofrequency ablation for lung cancers: A systematic review and meta-analysis. Eur J Radiol 100: 92-98, 2018.

30. Liu B, Ye X, Fan W, Li X, Feng W, Lu Q, Mao Y, Lin Z, Li L, Zhuang Y, et al: Expert consensus for image-guided radiofrequency ablation of pulmonary tumors (2018 version). Zhongguo Fei Ai Za Zhi 21: 76-88, 2018 (In Chinese).

31. Palussière J, Catena V and Buy X: Percutaneous thermal ablation of lung tumors-Radiofrequency, microwave and cryotherapy: Where are we going? Diagn Interv Imaging 98: 619-625, 2017.

32. Yamamoto A, Hamamoto S, Matsuoka T, Kageyama K, Jogo A, Sohgawa E, Okuma T, Hamuro M, Toyoshima M, Kawabe J, et al: Spontaneous regression of untreated tumors with immuno-radiofrequency ablation, RF ablation in combination with local injection of OK-432, in a patient with lung metastases of colon cancer. J Vasc Interv Radiol 28: 477-479, 2017. 
33. Wan J, Wu W and Zhang RQ: Local recurrence of small cell lung cancer following radiofrequency ablation is induced by HIF-1a expression in the transition zone. Oncol Rep 35: 1297-1308, 2016.

34. Lin CS, Liu TC, Lee MT, Yang SF and Tsao TC: Independent prognostic value of hypoxia-inducible factor 1-alpha expression in small cell lung cancer. Int J Med Sci 14: 785-790, 2017.

35. Shin JW, Cho DG, Choi SY, Park JK, Lee KY and Moon Y: Prognostic factors in stage IIB Non-small cell lung cancer according to the 8th edition of TNM Staging System. Korean J Thorac Cardiovasc Surg 52: 131-140, 2019.

36. Beland MD, Wasser EJ, Mayo-Smith WW and Dupuy DE: Primary non-small cell lung cancer: Review of frequency, location, and time of recurrence after radiofrequency ablation. Radiology 254: 301-317, 2010.

37. Poch FGM, Rieder C, Ballhausen H, Knappe V, Ritz JP Gemeinhardt O, Kreis ME and Lehmann KS: Finding optimal ablation parameters for multipolar radiofrequency ablation. Surg Innov 24: 205-213, 2017.

38. Prud'homme C, Deschamps F, Moulin B, Hakime A Al-Ahmar M, Moalla S, Roux C, Teriitehau C, de Baere T and Tselikas L: Image-guided lung metastasis ablation: A literature review. Int J Hyperthermia 36: 37-45, 2019.

39. Baisi A, Raveglia F, De Simone M and Cioffi U: Palliative role ofpercutaneous radiofrequency ablation for severe hemoptysisin an elderly patient with inoperable lung cancer. J Thorac Cardiovasc Surg 140: 1196-1197, 2010.

40. Tong Y, Yang H, Xu X, Ruan J, Liang M, Wu J and Luo B: Effect of a hypoxic microenvironment after radiofrequency ablation on residual hepatocellular cell migration and invasion. Cancer Sci 108: 753-762, 2017.

41. Mees G, Sathekge M, Maes A and Van de Wiele C: Radiolabelled probes targeting tumor hypoxia for personalized medicine. Curr Pharm Des 20: 2308-2318, 2014.

42. Wan J, Wu W, Chen Y, Kang N and Zhang R: Insufficient radiofrequency ablation promotes the growth of non-small cell lung cancer cells through PI3K/Akt/HIF-1 $\alpha$ signals. Acta Biochim Biophys Sin (Shanghai) 48: 371-377, 2016.

43. Wan J, Wu W, Huang Y, Ge W and Liu S: Incomplete radiofrequency ablation accelerates proliferation and angiogenesis of residual lung carcinomas via HSP70/HIF-1 $\alpha$. Oncol Rep 36 : 659-668, 2016

44. Pinato DJ, Black JR, Trousil S, Dina RE, Trivedi P, Mauri FA and Sharma R: Programmed cell death ligands expression in phaeochromocytomas and paragangliomas: Relationship with the hypoxic response, immune evasion and malignant behavior. Oncoimmunology 6: e1358332, 2017.

45. Cai FF, Xu C, Pan X, Cai L, Lin XY, Chen S and Biskup E: Prognostic value of plasma levels of HIF-1 $\alpha$ and PGC-1a in breast cancer. Oncotarget 7: 77793-77806, 2016.
46. Wan L, Huang J, Chen J, Wang R, Dong C, Lu S and Wu X: Expression and significance of FOXP1, HIF- $1 \alpha$ and VEGF in renal clear cell carcinoma. J BUON 20: 188-195, 2015.

47. Wachters JE, Schrijvers ML, Slagter-Menkema L, Mastik M, de Bock GH, Langendijk JA, Kluin PM, Schuuring E, van der Laan BF and van der Wal JE: Prognostic significance of HIF-1 $\alpha$, CA-IX, and OPN in T1-T2 laryngeal carcinoma treated with radiotherapy. Laryngoscope 123: 2154-2160, 2013.

48. Zhong H, De Marzo AM, Laughner E, Lim M, Hilton DA, Zagzag D, Buechler P, Isaacs WB, Semenza GL and Simons JW: Overexpression of hypoxia-inducible factor 1alpha in common human cancers and their metastases. Cancer Res 59: 5830-5835, 1999.

49. Kong J, Kong J, Pan B, Ke S, Dong S, Li X, Zhou A, Zheng L and Sun WB: Insufficient radiofrequency ablation promotes angiogenesis of residual hepatocellular carcinoma via HIF-1 $\alpha /$ VEGFA. PLoS One 7: e37266, 2012.

50. Morine Y, Shimada M, Utsunomiya T, Imura S, Ikemoto T, Mori H, Hanaoka J, Kanamoto M, Iwahashi S and Miyake H: Hypoxia inducible factor expression in intrahepatic cholangiocarcinoma. Hepatogastroenterology 58: 1439-1444, 2011.

51. Kitajima Y and Miyazaki K: The Critical impact of HIF-1 $\alpha$ on gastric cancer biology. Cancers (Basel) 5: 15-26, 2013.

52. Zhao X, Fu X, Blumenthal C, Wang YT, Jenkins MW, Snyder C, Arruda M and Rollins AM: Integrated RFA/PSOCT catheter for real-time guidance of cardiac radio-frequency ablation. Biomed Opt Express 9: 6400-6411, 2018

53. Wu W, Wan J, Xia R, Huang Z, Ni J and Yang M: Functional role of regulatory $\mathrm{T}$ cells in $\mathrm{B}$ cell lymphoma and related mechanisms. Int J Clin Exp Pathol 8: 9133-9139, 2015.

54. Bagrodia A, Krabbe LM, Gayed BA, Kapur P, Bernstein I, Xie XJ, Wood CG, Karam JA, Weizer AZ, Raman JD, et al: Evaluation of the prognostic significance of altered mammalian target of rapamycin pathway biomarkers in upper tract urothelial carcinoma. Urology 84: 1134-1140, 2014.

55. Karagoz B, Bilgi O, Gumus M, Erikci AA, Sayan O, Turken O, Kandemir EG, Oztürk A and Yaylaci M: CD8 ${ }^{+}$CD28-cells and $\mathrm{CD} 4{ }^{+} \mathrm{CD} 25^{+}$regulatory $\mathrm{T}$ cells in the peripheral blood of advanced stage lung cancer patients. Med Oncol 27: 29-33, 2010.

56. Ke X, Zhang S, Xu J, Liu G, Zhang L, Xie E, Gao L, Li D, Sun R, Wang F and Pan S: Non-small-cell lung cancer-induced immunosuppression by increased human regulatory $\mathrm{T}$ cells via Foxp3 promoter demethylation. Cancer Immunol Immunother 65: 587-599, 2016.

This work is licensed under a Creative Commons Attribution-NonCommercial-NoDerivatives 4.0 International (CC BY-NC-ND 4.0) License. 